\title{
Retention and Task Shifting in Human Resources for Health through Data Mining
}

\author{
Cheng-Kun Wang ${ }^{1,2}$ \\ ${ }^{1}$ Chung Hwa University of Medical Technology, Tainan City, Taiwan \\ ${ }^{2}$ E-Champ Dermatology Clinic, Tainan City, Taiwan \\ Correspondence: Cheng-Kun Wang, Ph.D., Dermatologist, No.332, Yuyi Road, East District, Tainan City 701, \\ Taiwan.
}

Received: February 24, 2017

Accepted: March 13, 2017

Online Published: March 30, 2017

doi:10.5539/ibr.v10n5p29

URL: https://doi.org/10.5539/ibr.v10n5p29

\begin{abstract}
Human resources for health (HRH) are the backbone of the healthcare system, but a shortage of medical manpower and the misdistribution of human resources are critical problems in the rural areas of many countries till 2017. The shortage of medical manpower is a big issue between 2004 and 2013. Data mining of bibliometrics is a good tool to find the solutions for shortage of medical manpower. By analyzing 118,092 citations in 2,000 articles published in the SSCI and SCI databases addressing HRH from 2004 to 2013, we plotted the networks among authors in the field. We combine quantitative bibliometrics and a qualitative literature review to determine the important articles and to realize the relationships between important topics in this field. We find that retention and task shifting are the hot topics in HRH field between 2004 and 2013, and find out the solutions for these issues through literature review in later papers. The solution to the HRH shortage is to determine the motivations of health workers and to provide incentives to maintain their retention. Task shifting is another solution to the HRH crisis.
\end{abstract}

Keywords: human resources, task shifting, motivation, retention, health system

\section{Introduction}

There is a broad consensus that shows qualified, accessible, and responsive human resources for health (HRH) can make a major impact on the health of the people. At the same time, there is widespread recognition that human resources for health (HRH) crises particularly in low- and middle-income countries (LMICs) impede the achievement of better health outcomes/targets (Lassi et al., 2016). The proposals for re-defining the roles Africa's health workforce have centred on basing the continent's healthcare delivery on non-physician clinicians (NPCs) who can be quickly trained and widely distributed to treat majority of the common diseases (Olapade-Olaopa, Sewankambo, \& Iputo, 2017). The shortage of medical manpower is a big issue between 2004 and 2013. Data mining of bibliometrics is a good tool to find the solutions for shortage of medical manpower.

The shortage of medical manpower and the misdistribution of human resources are critical problems in the rural areas of many countries till 2017. Quality health care depends on policies to ensure that health workers are available in sufficient numbers (World Health Organization, 2006). The health workforce is the backbone of every health system (Anyangwe \& Mtonga, 2007). The workforce utilization of human resources for health (HRH) is a key component of effective health service delivery (Suter et al., 2014). Challenges related to human resources for health $(\mathrm{HRH})$ are important in low- and middle-income countries. These challenges include shortages of staff, shortages of health workers in remote rural districts, staff absenteeism and poor motivation. These problems are likely caused by low pay, poor supervision and support, and unsatisfactory working conditions (Chopra, Munro, Lavis, Vist, \& Bennett, 2008). A higher density of health workers and nurses increases the availability of vaccination services, and a shortage of HRH can significantly constrain vaccination coverage in developing countries. The density of HRH is important to the rates of maternal mortality, infant mortality, and mortality under five years of age (Anand \& Bärnighausen, 2004).

In order to achieve the Sustainable Development Goals (SDGs), equitable access to a skilled and motivated health worker within a performing health system is need to be ensured (Lassi et al., 2016). The recruitment and retention of health professionals in remote and rural areas is challenging; a lack of heal th professionals correlates 
with the poorer health status of remote and rural residents (Campbell, McAllister, \& Eley, 2012). Motivation is 'an indi vidual's degree of willingness to exert and maintain effort towards organizational goals' (Franco, Bennett, \& Kanfer, 2002). Health worker retention is critical for health system performance. The key is determining how to motivate and retain health workers; both financial and non-financial incentives affect motivation and retention (Willis-Shattuck et al., 2008).

In Africa, task shifting offers high-quality, cost-effective care to more patients than a physician-centered model. The primary challenges regarding implementation include adequate and sustainable training, support and pay for staff in new roles, integrating new members in the medical team, and compliance with regulatory bodies (Callaghan, Ford, \& Schneider, 2010). Substitute health workers assume some of the functions and roles reserved for health professionals, such as doctors, nurses and pharmacists. However, substitute health workers likely receive less medical training and possess fewer qualifications (Dovlo, 2004).

In this study, a bibliometric analysis of popular articles was adopted. Wagstaff and Culyer used bibliometrics to examine the last forty years of health economics. They used bibliographic "metadata" from EconLit supplemented by citation data from Google Scholar to report the development of health economics (Wagstaff \& Culyer, 2012). Social networking posits that each person is part of a sub-set of familiar people. This network can be represented as a set of points (or vertices) joined in pairs by the lines (or edges) that meet. One could, in principle, build a social network for a company, firm, school, university, other community or the entire world (Newman, 2001). A famous early empirical study of the structure of social networks was conducted by Stanley Milgram (Milgram, 1967). We used a co-citation analysis method to create a virtual social network among scholars.

After the bibliometric analysis, we found that the hot issue in many HRH papers was the shortage of health workers and how to retain them. Many authors provided methods to improve health workers' motivation. As the health worker shortage continues, how to use task shifting to achieve high performance for health care was also a concern. This study determined the popular topics and then depicted the social HRH networks among researchers. This study then went further and explored how to use health workers to maintain and improve the quality of health care.

\section{Method}

In this study, the well-recognized high-quality databases Science Citation Index (SCI) and Social Sciences Citation Index (SSCI) were adopted. First, we used bibliometric method to determine the quantity of popular journal papers, popular authors and popular keywords. Second, we adopted social network analysis to identify eight popular issues in the HRH field. Finally, a qualitative literature review was performed. The goal of this study is to provide virtual social HRH networks and thereby understand the relationships between the authors on these topics. This study also attempts to identify the authors' contributions in the field. On this basis, this study used citation data from the literature regarding HRH from 2004 to 2013. We searched the terms "human resources" and "health" in journals listed in the SSCI and the SCI. We selected the top-ranking 1,000 papers (times-cited ranking, highly cited ranking) in each five-year period (2004-2008, 2009-2013). Finally, we analyzed 118,092 citations of 2,000 articles from 2004-2013. The citation data used in this study include journal articles, authors, keywords, and cited references.

The structure of scientific collaboration networks was studied by Newman (2001). Two scientists are considered to be connected if they have authored a paper together, and explicit networks of these connections are constructed by using data obtained from many databases (Newman, 2001). The networks mentioned by Newman were the "real" social networks. We attempted to define a "virtual" social network. One paper that cited two different authors at the same time was called a "co-citation": there was some relationship between these two different authors. Therefore, these two authors produce a link in the virtual social network. Co-citation analysis is a bibliometric technique that scientists use to map the intellectual structure of an academic field and involves counting documents from paired or co-cited documents. The analysis compiles co-citation counts in a matrix form and statistically scales them to capture a snapshot at a distinct point of the knowledge structure (Small, 1993).

Citation and co-citation analysis are the primary methods used in this study. First, the databases were identified as the sources of HRH publications. Then, data collection and analysis techniques were designed to collect information regarding topics and authors in HRH research. The collected data were analyzed and systematized by sorting, screening, summing, sub-totaling, and ranking. The data were run through the UCINET software (Borgatti, Everett, \& Freeman, 2002). After a series of operations, key nodes were identified in the invisible network of HRH knowledge. Finally, co-citation analysis was used, and it revealed the virtual social HRH network. The networks were mapped to describe "author factions" in the field of HRH. 


\section{Results}

After analyzing the 118,092 citations from 2,000 HRH articles published in the SSCI and SCI journals from 2004 to 2013, a timeline of the most cited authors and papers was developed. The detailed data included 56,087 citations of 1,000 articles from 2004 to 2008 and 62,005 citations of 1,000 articles from 2009 to 2013.

\subsection{Citation Analysis and Development of the Timeline}

Table 1 shows the historical timeline for HRH issues in the database. The frequency of citation (times cited) indicates the importance of the article. The most influential article is assumed to be the most frequently cited.

Table 1. Timeline of human resources for health articles (citations from SSCI and SCI articles, 2009-2013)

\begin{tabular}{|c|c|c|c|c|c|c|c|}
\hline Year & $\begin{array}{l}\text { Frequency } \\
\text { /times cited }\end{array}$ & $\mathrm{B} / \mathrm{J}^{*}$ & Author & Year & & & \\
\hline 2004 & 39 & $\mathrm{~J}$ & Chen L & 2004 & Lancet & V364 & P1984 \\
\hline 2004 & 18 & $\mathrm{~J}$ & Dovlo D & 2004 & Hum Resour Health & $\mathrm{V} 2$ & P7 \\
\hline 2004 & 17 & $\mathrm{~J}$ & Hongoro $\mathrm{C}$ & 2004 & Lancet & V364 & P1451 \\
\hline 2004 & 13 & $\mathrm{~J}$ & Kober K & 2004 & Lancet & V364 & P103 \\
\hline 2004 & 11 & $\mathrm{~J}$ & Anand S & 2004 & Lancet & V364 & P1603 \\
\hline 2006 & 39 & B & $\begin{array}{ll}\text { World } & \text { Health } \\
\text { Organization } & \end{array}$ & 2006 & World Hlth Rep 2006 & & \\
\hline 2006 & 13 & $\mathrm{~J}$ & Stringer Jsa & 2006 & Jama-J Am Med Assoc & V296 & P782 \\
\hline 2006 & 12 & $\mathrm{~J}$ & Braitstein $\mathrm{P}$ & 2006 & Lancet & V367 & P817 \\
\hline 2006 & 12 & $\mathrm{~J}$ & Van Damme W & 2006 & Aids & V20 & P653 \\
\hline 2006 & 12 & $\mathrm{~J}$ & Gilks Cf & 2006 & Lancet & V368 & P505 \\
\hline 2006 & 11 & $\mathrm{~J}$ & Schneider $\mathrm{H}$ & 2006 & Reprod Health Matter & V14 & P12 \\
\hline 2006 & 10 & $\mathrm{~J}$ & Gandhi $\mathrm{Nr}$ & 2006 & Lancet & V368 & P1575 \\
\hline 2006 & 10 & $\mathrm{~B}$ & $\begin{array}{ll}\text { World } & \text { Health } \\
\text { Organization (Who) }\end{array}$ & 2006 & Ant Ther Hiv Inf Ad & & \\
\hline 2006 & 10 & $\mathrm{~B}$ & $\begin{array}{ll}\text { World } & \text { Health } \\
\text { Organization } & \end{array}$ & 2006 & Work Tog Hlth World & & \\
\hline 2007 & 23 & $\mathrm{~J}$ & Samb B & 2007 & New Engl J Med & V357 & $\mathrm{P} 2510$ \\
\hline 2007 & 14 & $\mathrm{~J}$ & Mullan F & 2007 & Lancet & V370 & P2158 \\
\hline 2007 & 12 & $\mathrm{~J}$ & Rosen $\mathrm{S}$ & 2007 & Plos Med & V4 & P1691 \\
\hline 2007 & 11 & B & $\begin{array}{ll}\text { World } & \text { Health } \\
\text { Organization } & \end{array}$ & 2007 & Ev Bus Strength Hlth & & \\
\hline 2008 & 15 & $\mathrm{~J}$ & Philips M & 2008 & Lancet & V371 & P682 \\
\hline 2008 & 11 & $\mathrm{~J}$ & Van Damme W & 2008 & Soc Sci Med & V66 & P2108 \\
\hline 2008 & 10 & B & Who & 2008 & Task Shift Rat Red T & & \\
\hline 2008 & 9 & $\mathrm{~J}$ & Lawn Sd & 2008 & Aids & V22 & P1897 \\
\hline 2008 & 9 & $\mathrm{~J}$ & Lehmann U & 2008 & Bmc Health Serv Res & V8 & \\
\hline 2008 & 9 & $\mathrm{~J}$ & Chopra M & 2008 & Lancet & V371 & P668 \\
\hline 2008 & 8 & B & $\begin{array}{l}\text { World } \\
\text { Organization }\end{array}$ & 2008 & Whohtmtb2008393 & & \\
\hline 2008 & 8 & $\mathrm{~J}$ & Weiser Tg & 2008 & Lancet & V372 & P139 \\
\hline 2008 & 8 & $\mathrm{~J}$ & Ooms G & 2008 & Globalization Health & V4 & \\
\hline 2008 & 8 & B & Who & 2008 & Glob Burd Dis $2004 \mathrm{U}$ & & \\
\hline 2008 & 8 & $\mathrm{~J}$ & Collins Fs & 2008 & Science & V319 & P906 \\
\hline 2008 & 8 & $\mathrm{~J}$ & Jones $\mathrm{Ke}$ & 2008 & Nature & V451 & P990 \\
\hline 2009 & 14 & $\mathrm{~J}$ & Granich Rm & 2009 & Lancet & V373 & P48 \\
\hline 2009 & 10 & $\mathrm{~J}$ & Sankaranarayanan $\mathrm{R}$ & 2009 & New Engl J Med & V360 & P1385 \\
\hline 2010 & 9 & $\mathrm{~J}$ & Callaghan M & 2010 & Hum Resour Health & V8 & \\
\hline 2010 & 8 & B & $\begin{array}{l}\text { World } \\
\text { Organization }\end{array}$ & 2010 & Ant Ther Hiv Inf Ad & & \\
\hline
\end{tabular}

B/J: B:Book, J:Journal

\subsection{Keyword Analysis Reveals Research Trends}

Table 2 shows the keyword analysis of 2,000 articles published in the SSCI and SCI journals. We compared the keywords between the two five-year periods (2004-2008 and 2009-2013). Most of the keywords focused on HRH in Africa and HIV (human immunodeficiency virus) care. 
Table 2. Analysis of keywords of 2,000 articles between the two five-year periods

\begin{tabular}{llll}
\hline $2004-2008$ & Frequency & 2009-2013 & Frequency \\
\hline human-immunodeficiency-virus & 82 & health & 77 \\
health & 82 & human-immunodeficiency-virus & 61 \\
care & 59 & care & 55 \\
united-states & 56 & united-states & 52 \\
mortality & 39 & sub-saharan africa & 42 \\
developing-countries & 39 & south-africa & 40 \\
management & 38 & mortality & 40 \\
children & 32 & impact & 37 \\
randomized controlled-trial & 29 & developing-countries & 34 \\
health-care & 28 & randomized controlled-trial & 34 \\
prevalence & 28 & management & 34 \\
human-resources & 27 & human-resources & 33 \\
impact & 27 & countries & 32 \\
infection & 27 & health-care & 32 \\
active antiretroviral therapy & 24 & risk & 30 \\
risk & 24 & africa & 29 \\
south-africa & 23 & model & 28 \\
sub-saharan africa & 23 & therapy & 28 \\
transmission & 22 & outcomes & 27 \\
aids & 22 & antiretroviral therapy & 27 \\
\hline
\end{tabular}

3.3 Co-Citation Analysis

If one paper cited two different authors at the same time, it was called a "co-citation": there was some relationship between these two authors. The first five-year virtual social network diagram (Figure 1) for 20042008 was different from the second diagram (Figure 2) for 2009-2013.

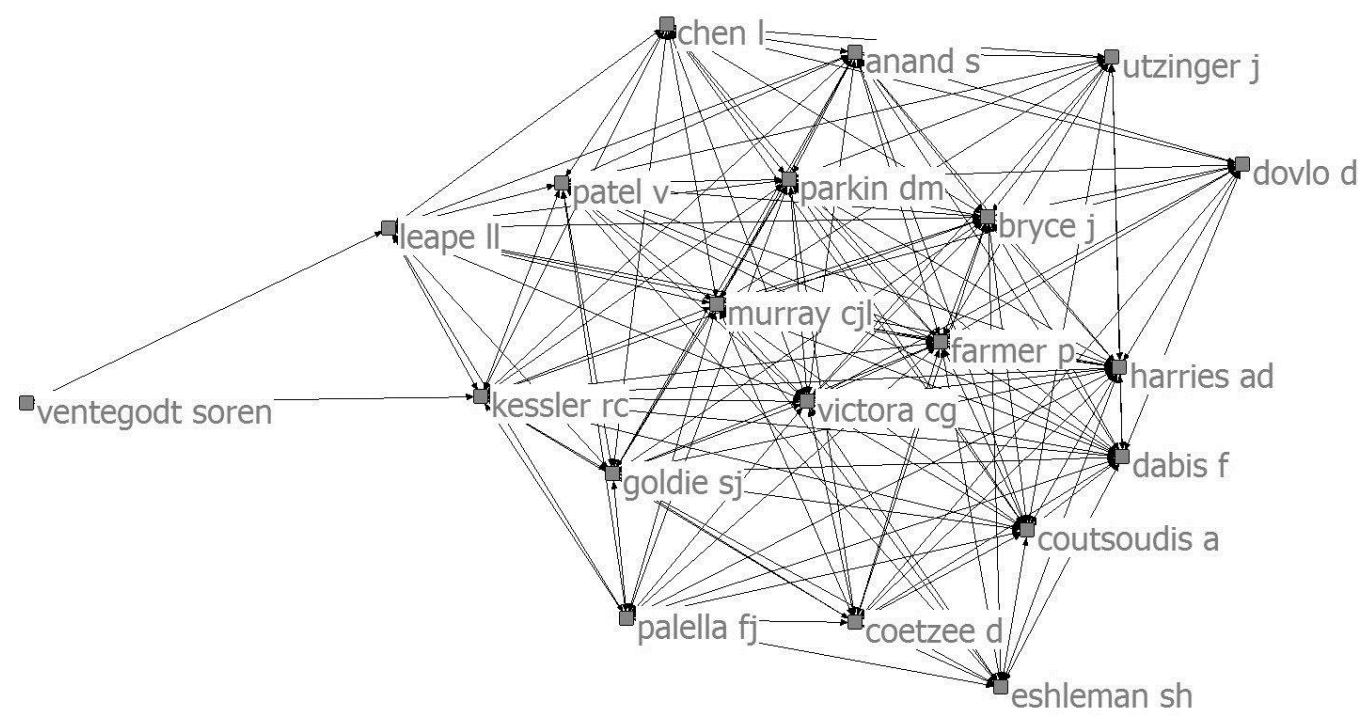

Figure 1. Key research themes of authors in human resources for health (2004-2008): virtual social network diagram

We adopted a factor analysis to distinguish the groups of authors into different factions. Virtual social network analysis techniques were used to plot the relationships in the co-citation matrix. We identified the strongest connections and the important authors. Figures 1 and 2 show the research themes of the authors in HRH studies. Different node shapes appeared after performing a "faction study" of these authors (Wang, McLee, \& Kuo, 2011). This method groups elements in a network based on the sharing of common connections to one another. The few scholars in Figures 1 and 2 with the most links (co-citation) are the important persons in HRH research. For these scholars, there were heavy and dense links, and these core authors occupied advantageous positions in health care research; their publications and research revealed the research development trend in this field. 


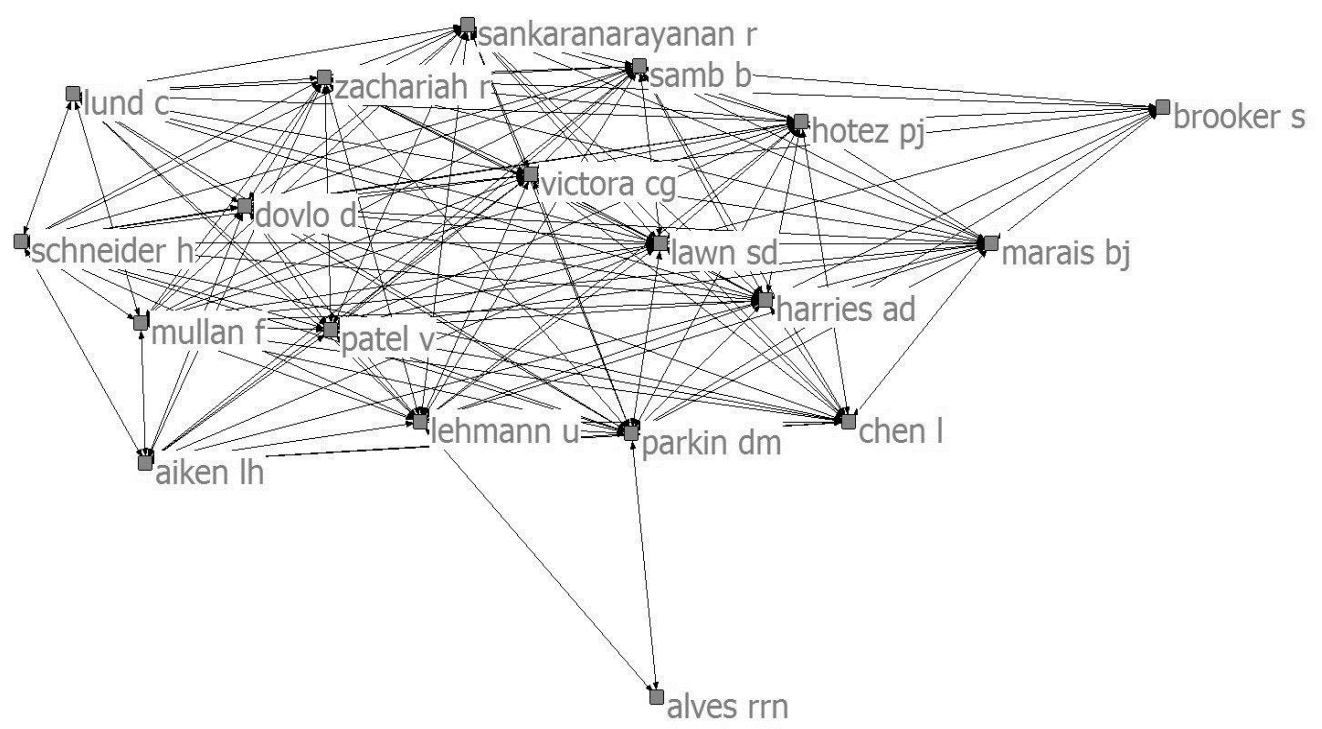

Figure 2. Key research themes of authors in human resources for health (2009-2013): virtual social network diagram

Although the diagrams in Figures 1 and 2 provide a clear picture, they focus on only the core areas. The important authors are the core of the network. Figure 1 represents the first five-year interval, and Figure 2 represents the next five-year interval. We compared the cores of both networks and located the paradigm shift in the authors between the two periods.

By using the co-citation matrix and factor analysis, the correlations among the authors were analyzed. When the authors are grouped together, there are common elements among them. According to this analysis, the closeness of these authors revealed their algorithmic similarities as perceived by the citers (Wang et al., 2011). The co-citation correlation matrix was factor analyzed with varimax rotation, a common procedure that attempts to fit (or load) the maximum number of authors with the minimum number of factors (McCain, 1990).

Table 3. Author factor loadings: 2009-2013

\begin{tabular}{|c|c|c|c|c|c|}
\hline $2009-2013$ & & Name of group & & & Name of group \\
\hline factor1 & variance & $\begin{array}{l}\text { HIV care and task } \\
\text { shifting }\end{array}$ & factor 2 & variance & Staffing and education \\
\hline Samb B & 0.957 & & Mullan F & 0.965 & \\
\hline Marais $\mathrm{Bj}$ & 0.871 & & Aiken Lh & 0.909 & \\
\hline Lawn Sd & 0.853 & & & & \\
\hline Zachariah $\mathrm{R}$ & 0.816 & & & & \\
\hline Schneider $\mathrm{H}$ & 0.773 & & & & \\
\hline Harries Ad & 0.603 & & & & \\
\hline factor3 & variance & Cancer survival & factor4 & variance & $\begin{array}{l}\text { Low- and middle-income } \\
\text { countries }\end{array}$ \\
\hline Alves Rrn & 0.903 & & Lund C & 0.842 & \\
\hline Sankaranarayanan $\mathrm{R}$ & 0.802 & & Chen L & 0.792 & \\
\hline factor5 & variance & $\begin{array}{l}\text { Maternal and } \\
\text { child health }\end{array}$ & factor6 & variance & Infection \\
\hline Brooker S & 0.876 & & Patel V & 0.77 & \\
\hline Victora $\mathrm{Cg}$ & 0.63 & & Hotez $\mathrm{Pj}$ & 0.705 & \\
\hline factor7 & variance & $\begin{array}{l}\text { Sub-Saharan } \\
\text { Africa }\end{array}$ & factor8 & variance & Cancer mortality \\
\hline Dovlo D & 0.9 & & Parkin Dm & 0.915 & \\
\hline
\end{tabular}

Eight factors were extracted from the data from 2009 to 2013; together, they explained over $78.6 \%$ of the variance in the correlation matrix. Table 3 lists the 8 most important factors and the authors that had a factor loading of at least 0.5 . As is usual in this type of analysis, authors with less than a 0.5 loading were dropped from the results (White \& Griffith, 1981). We tentatively assigned names to the factors on the basis of our own interpretation of the authors with high loadings. Our interpretation of the results is that HRH research from 
2009-2013 comprises at least the following 8 different sub-fields: HIV care, staffing and education, cancer survival, low and middle income countries, maternal and child health, infection, Sub-Saharan Africa and cancer mortality (see Table 3). We made no attempt to interpret the remaining factors because of their small eigenvalues.

\section{Discussion}

\subsection{The Findings from the Timeline, the Keyword Analysis and the Co-Citation Analysis}

We find the hot topics are retention and task shifting in HRH field. Chen, shown with 39 citations in Table 1, indicated that nearly all countries are challenged by worker shortages, skill-mix imbalances, misdistribution, poor work environments, and weak knowledge training. Especially in the poorest countries, the workforce is affected by HIV/AIDS, out-migration, and inadequate investment (Chen et al., 2004). Lehmann, shown with 9 citations in Table 1, focused on staffing remote rural areas in middle- and low-income countries. Concerning the attraction and retention of health workers, there is a strong argument for interventions that include attention to living and working environments and conditions and to development opportunities (Lehmann, Dieleman, \& Martineau, 2008). Chopra, shown with 9 citations in Table 1, examined the effects of policy options for HRH. There were several important issues for human resources, such as substitution, shifting tasks between different types of health workers, or extending their roles. Performance-enhancing strategies drew researchers' attention, such as quality improvement, continuing education strategies, promotion of teamwork, and changes to workflows (Chopra et al., 2008). Callaghan, shown with 9 citations in Table 1, focused on task shifting for HIV treatment and care in Africa. Task shifting is a viable and rapid response to Sub-Saharan Africa's human resource crisis in HIV care (Callaghan et al., 2010).

The keywords arranged in front were important themes. After a critical qualitative literature review, a subjective selection of popular keywords was performed. We chose the hot keywords, such as human immunodeficiency virus, Sub-Saharan Africa, de veloping countries and antiretroviral therapy. Most of the important keywords revealed that task shifting to assist with HIV care in Africa is valuable.

The social networks of the co-citation analysis revealed that from 2009 to 2013, Samb b, Sankaranarayanan r, Zachariah r, Hotez pj, Lawn sd, Mullan $\mathrm{f}$ and Lehmann u appeared in the core network with Victora cg, Dovlo d, Parkin dm, Patel v and Chen 1. The paradigm shift in HRH research revealed that Samb b, Sankaranarayanan r, Zachariah r, Hotez pj, Lawn sd, Mullan $\mathrm{f}$ and Lehmann u joined the evolving trend in this field. Lehmann u focused on task shifting for the human resource crisis in Africa. Mullan $f$ examined the metrics of physician brain drain. Lawn sd studied promoting the retention of antiretroviral treatment services in South Africa. Hotez pj assessed infectious diseases in Africa. Zachariah $r$ investigated task shifting in HIV/AIDS in Sub-Saharan Africa. Sankaranarayanan $r$ examined cryotherapy by nurses in cervical cancer. Samb b focused on task shifting in HIV care in terms of nurse-centered community-based care.

\subsection{Migration and Brain Drain}

International migration is widely blamed for the shortage of health workers, and certainly, many health workers are moving to developed countries (Hongoro \& Normand, 2006). Currently, many hospitals in middle- and low-income countries suffer from staff shortages and/or the mis distribution of health workers (Lehmann et al., 2008). The migration of doctors and nurses resembles a carousel of multiple entry and exit paths from low- to high-income regions and countries (Chen et al., 2004). In most developing countries, the health workforce is concentrated in larger cities and capitals, whereas rural areas attract few doctors and nurses (Anyangwe \& Mtonga, 2007). Brain drain has also weakened the workforce of doctors in many poor countries and limits the ability of these countries to respond to HIV infections, AIDS, and other pressing needs (Mullan, 2005).

Many health workers seek a better life and more rewarding work by departing for wealthier countries (Chen et al., 2004). Low wages, poor working conditions, and a lack of supervision, equipment and infrastructure contribute to the flight of health workers from remote areas (Lehmann et al., 2008). Nurse migration has been shown to be motivated by the need for professional development, better quality of life and personal safety (Kingma, 2001). Female health workers tend to avoid rural and remote areas (Dussault \& Franceschini, 2006). Doctors and nurses are reluctant to relocate to remote areas with poor communication with the rest of the country and a less comfortable environment for health professionals and their families (Dussault \& Franceschini, 2006). A 'medical carousel' whereby health workers move to wealthy countries leaves the poorest countries with limited resources. Staff shortages increase the workloads and stress levels of remaining staff. To manage an increased workload, staff must sometimes lower the quality of care (Willis-Shattuck et al., 2008).

Regarding the migration of health workers, there is internal migration within a country and international 
migration to other countries. Internal migration always occurs from rural areas to cities. International migration always occurs from poor to rich countries. Low job satisfaction and a lack of incentives affect the performance of health workers and cause them to leave. Therefore, good policy decisions must be made to prevent health workers from migrating. A sufficient number of health workers must remain to maintain the quality of health care.

\subsection{Retention of Health Workers}

The following motivational themes for health workers were identified: financial rewards, career development, continuing education, hospital infrastructure, resource availability, hospital management, recognition and appreciation. There was some evidence that initiatives to improve motivation have been effective in maintaining retention. Financial incentives, career development and management issues are core factors (Willis-Shattuck et al., 2008). Low salaries and unsatisfactory working conditions are reasons for not practicing in rural and remote areas (Dussault \& Franceschini, 2006). Several incentives were found to be effective in retaining staff in rural areas. These incentives included providing housing and transportation, agreeing to the number of years that would be spent in the rural location, offering medical training, and offering financial incentives (Stilwell et al., 2004). Continuing professional development improves professional job satisfaction and may support rural recruitment and the retention of doctors and health workers (Wilson et al., 2009). Improving the social and professional recognition of health professionals in remote areas was another method of motivation (Dussault \& Franceschini, 2006).

The way to retain health workers is to discover their motivations and provide them with incentives. These strategies include increasing salaries, providing continuous medical training and career development programs, maintaining good relationships among medical team members, improving the infrastructure and equipment in hospitals, and providing sufficient medication and materials.

\subsection{Task Shifting}

Since the 2006 World Health Report advocated increased community participation and the systematic delegation of tasks to less-specialized personnel, there have been many debates regarding the efficacy, modalities and expediency of task shifting (Lehmann, Van Damme, Barten, \& Sanders, 2009). The opportunities from task shifting include increasing access to health care, expanding the workforce skills mix, improving health-system efficiency, enhancing the role of the community, and reducing costs, attrition and international 'brain drain'. The challenges of task shifting include maintaining medical quality and patient safety, addressing professional and institutional resistance, sustaining motivation and performance, and preventing the deaths of health workers from infectious diseases (Zachariah et al., 2009).

The delegation of medical tasks from one cadre to another has been used for many decades to enhance quality and reduce costs, especially in understaffed rural areas (Lehmann et al., 2009). In Africa, non-physician clinicians have been trained to fill various roles. Good health outcomes can be achieved by shifting tasks to nurses and community health workers (Callaghan et al., 2010). Non-physician clinicians (NPCs) are not trained as physicians but assume many of the diagnostic and clinical functions of medical doctors. All NPCs performed basic diagnosis and medical treatment. Many NPCs were recruited from rural and poor areas and worked in these regions. Low training costs, short training durations, and success in rural placements suggest that NPCs can play a substantial role in the expansion of health workforces in Afric an countries in terms of HIV/AIDS care (Mullan \& Frehywot, 2008).

The potential for task shifting in HIV care was elaborated by the World Health Organization, which suggested that nurses and health workers could be trained to provide primary care to HIV patients (Callaghan et al., 2010). Nurse-managed antiretroviral therapy (ART) for HIV infections was not inferior to doctor-managed ART in Africa: both treatment services had similar outcomes for viral suppression, adherence, toxicity and death (Sanne et al., 2010). Delegating tasks can improve the coverage and quality of and access to health services (Lehmann et al., 2009). Efforts at improving Africa's health systems can only succeed if the necessary socio-economic, educational, and technological infrastructure are in place (Olapade-Olaopa et al., 2017).

Task shifting is recognized as a valuable method to solve the HRH crisis. Non-physician clinicians (NPCs) are also more likely to remain in their rural communities and provide primary care. The government must promote the implementation of related policies regarding task shifting when an HRH shortage occurs. Good leadership from a regulatory framework is indispensable. The continuous medical training of NPCs ensures that there are adequate, qualified HRH. Task shifting can provide sustainable contributions from cost-effective and equitable health care, but there are several risks, such as misdiagnosis and administering the wrong medicine and treatment. Therefore, the government must oversee task shifting to ensure adherence to regulations and appropriate training and financing. 
We find that retention and task shifting are the hot topics in HRH field between 2004 and 2013, and find out the solutions for these issues through literature review in later papers.

\subsection{Contributions to Scholarship}

This study analyzed the citation data for various papers addressing HRH, identified similar themes across various researchers, and determined the hot topics being discussed through a qualitative method. We adopted bibliometric methods to generate quantitative data and then identified important $\mathrm{HRH}$ issues using subjective judgment. Finally, we adopted a qualitative literature review to explore the important issues. This study is a mixed method of quantitative and qualitative research. The qualitative literature review of frequently cited papers provokes critical thinking regarding HRH.

Our interpretation of the results is that HRH research from 2009-2013 comprises at least the following 8 different sub-fields: HIV care; staffing and education; cancer survival; low- and middle-income countries; maternal and child health; infection; Sub-Saharan Africa; and cancer mortality. Therefore, we discussed motivations, incentives, retention and task shifting in HRH.

The improvement of many health outcomes cannot be achieved if vulnerable populations do not have access to skilled medical personnel (Dussault \& Franceschini, 2006). High-income countries have shown that increased numbers of nursing staff were associated with improved inpatient outcomes. Reduced workflow or workl oad can increase efficiency in high-income countries. Teamwork, defined as interventions to improve the collaboration between doctors and nurses, was shown to be a promising intervention, with the potential to reduce costs and positively affect practitioners and patients (Chopra et al., 2008). Policy options in HRH include training, regulations, financing, organizational mechanisms, macro policies and mechanisms in other sectors (Chopra et al., 2008).

\subsection{Applied Implications}

HRH are the core component of medical systems. To resolve the shortage in health care personnel, policy makers may consider the following options: recruiting health workers to practice in rural areas; improving their working and living conditions; providing incentives; requiring compulsory service; changing or discontinuing services; improving hospital infrastructure and equipment; changing workflows; developing alternative service delivery systems and using substitute personnel (task shifting).

In countries around the world, the lack of medical personnel, uneven distribution of medical personnel and medical brain drain were significant problems. These problems will increase maternal and infant mortality, cancer mortality, infection rates, HIV pre valence and mortality, etc. Therefore, the development of strategies to solve the HRH crisis is an important issue. Beyond the role of government and the private sector, every organization must confront the shortage of medical personnel. After a qualitative literature review, we discovered several possible responses. The solution for HRH is to discover the motivations of health workers and to provide incentives to maintain their retention. Task shifting is another solution to the HRH crisis.

\subsection{Limitations and Future Research Directions}

The citations used in this study are the voting behaviors of many authors. However, the citations are from old articles. Citation analysis can find the pre vious paradigm and paradigm shift, but some authors are too new to be cited. Thus, we cannot identify the important authors in the future, but we can find the research trends.

\section{References}

Anand, S., \& Bärnighausen, T. (2004). Human resources and health outcomes: Cross-country econometric study. The Lancet, 364(9445), 1603-1609. https://doi.org/10.1016/S0140-6736(04)17313-3

Anyangwe, S. C., \& Mtonga, C. (2007). Inequities in the global health workforce: The greatest impediment to health in sub-saharan africa. International Journal of Environmental Research and Public Health, 4(2), 93-100. https://doi.org/10.3390/ijerph2007040002

Borgatti, S. P., Everett, M. G., \& Freeman, L. C. (2002). Ucinet for windows: Software for social network analysis.

Callaghan, M., Ford, N., \& Schneider, H. (2010). A systematic review of task-shifting for HIV treatment and care in africa. Human Resources for Health, 8, 8-16. https://doi.org/10.1186/1478-4491-8-8

Campbell, N., McAllister, L., \& Eley, D. (2012). The influence of motivation in recruitment and retention of rural and remote allied health professionals: A literature review. Rural and Remote Health, 12(1900). 
Chen, L., Evans, T., Anand, S., Boufford, J. I., Brown, H., Chowdhury, M., . . Elzinga, G. (2004). Human resources for health: Overcoming the crisis. The Lancet, 364(9449), 1984-1990. https://doi.org/10.1016/S0140-6736(04)17482-5

Chopra, M., Munro, S., Lavis, J. N., Vist, G., \& Bennett, S. (2008). Effects of policy options for human resources for health: An analysis of systematic reviews. The Lancet, 371(9613), 668-674. https://doi.org/10.1016/S0140-6736(08)60305-0

Dovlo, D. (2004). Using mid-level cadres as substitutes for internationally mobile health professionals in africa. A desk review. Human Resourcesfor Health, 2(1), 7. https://doi.org/10.1186/1478-4491-2-7

Dussault, G., \& Franceschini, M. C. (2006). Not enough there, too many here: Understanding geographical imbalances in the distribution of the health workforce. Human Resources for Health, 4(1), 12. https://doi.org/10.1186/1478-4491-4-12

Franco, L. M., Bennett, S., \& Kanfer, R. (2002). Health sector reform and public sector health worker motivation: A conceptual framework. Social Science \& Medicine, 54(8), 1255-1266. https://doi.org/10.1016/S0277-9536(01)00094-6

Hongoro, C., \& Normand, C. (2006). Health workers: Building and motivating the workforce. Disease Control Priorities in Developing Countries, 71, 1309-1322.

Kingma, M. (2001). Nursing migration: Global treasure hunt or disaster - in - the - making? Nursing Inquiry, 8(4), 205-212. https://doi.org/10.1046/j.1440-1800.2001.00116.x

Lassi, Z. S., Musavi, N. B., Maliqi, B., Mansoor, N., de Francisco, A., Toure, K., \& Bhutta, Z. A. (2016). Systematic review on human resources for health interventions to improve maternal health outcomes: Evidence from low-and middle-income countries. Human Resources for Health, 14(1), 1. https://doi.org/10.1186/s12960-016-0106-y

Lehmann, U., Dieleman, M., \& Martineau, T. (2008). Staffing remote rural areas in middle-and low-income countries: A literature review of attraction and retention. BMC Health Services Research, 8(1), 19. https://doi.org/10.1186/1472-6963-8-19

Lehmann, U., Van Damme, W., Barten, F., \& Sanders, D. (2009). Task shifting: The answer to the human resources crisis in africa? Human Resources for Health, 7(1), 49. https://doi.org/10.1186/1478-4491-7-49

McCain, K. W. (1990). Mapping authors in intellectual space: A technical overview. Journal of the American Society for Information Science, 41(6), 433-443. https://doi.org/10.1002/(SICI) 1097-4571(199009)41:6<433::AID-ASI1 1>3.0.CO;2-Q

Milgram, S. (1967). The small world problem. Psychology Today, 2(1), 60-67.

Mullan, F. (2005). The metrics of the physician brain drain. New England Journal of Medicine, 353(17), 1810-1818. https://doi.org/10.1056/NEJMsa050004

Mullan, F., \& Frehywot, S. (2008). Non-physician clinicians in 47 sub-saharan african countries. The Lancet, 370(9605), 2158-2163. https://doi.org/10.1016/S0140-6736(07)60785-5

Newman, M. E. (2001). The structure of scientific collaboration networks. Proceedings of the National Academy of Sciences of the United States of America, 98(2), 404-409. https://doi.org/10.1073/pnas.021544898

Olapade-Olaopa, E., Sewankambo, N., \& Iputo, J. (2017). Defining sub-saharan africa's health workforce needs: Going forwards quickly into the past: Comment on "Non-physician clinicians in sub-saharan africa and the evolving role of physicians.". International Journal of Health Policy and Management, 6(2), 111-113. https://doi.org/10.15171/ijhpm.2016.100

Sanne, I., Orrell, C., Fox, M. P., Conradie, F., Ive, P., Zeinecker, J., . . CIPRA-SA Study Team. (2010). Nurse versus doctor management of HIV-infected patients receiving antiretroviral therapy (CIPRA-SA): A randomised non-inferiority trial. Lancet, 376(9734), 33-40.

https://doi.org/10.1016/S0140-6736(10)60894-X

Small, H. (1993). Macro-level changes in the structure of co-citation clusters: 1983-1989. Scientometrics, 26(1), 5-20. https://doi.org/10.1007/BF02016789

Stilwell, B., Diallo, K., Zurn, P., Vujicic, M., Adams, O., \& Dal Poz, M. (2004). Migration of health-care workers from developing countries: Strategic approaches to its management. Bulletin of the World Health Organization, 82(8), 595-600. 
Suter, E., Deutschlander, S., Makwarimba, E., Wilhelm, A., Jackson, K., \& Lyons, S. W. (2014). Workforce utilization in three continuing care facilities. Health Sociology Review, 23(1), 65-76. https://doi.org/10.5172/hesr.2014.23.1.65

Wagstaff, A., \& Culyer, A. J. (2012). Four decades of health economics through a bibliometric lens. Journal of Health Economics, 31(2), 406-439. https://doi.org/10.1016/j.jhealeco.2012.03.002

Wang, C., McLee, Y., \& Kuo, J. (2011). Mapping the intellectual structure of digital divide. International Journal of Social Science Humanity, 1(1), 49-54. https://doi.org/10.7763/IJSSH.2011.V1.9

White, H. D., \& Griffith, B. C. (1981). Author cocitation: A literature measure of intellectual structure. Journal of the American Society for Information Science, 32 (3), 163-171. https://doi.org/10.1002/asi.4630320302

Willis-Shattuck, M., Bidwell, P., Thomas, S., Wyness, L., Blaauw, D., \& Ditlopo, P. (2008). Motivation and retention of health workers in developing countries: A systematic review. BMC Health Services Research, 8(1), 247. https://doi.org/10.1186/1472-6963-8-247

Wilson, N., Couper, I., De Vries, E., Reid, S., Fish, T., \& Marais, B. (2009). A critical review of interventions to redress the inequitable distribution of healthcare professionals to rural and remote areas. Rural and Remote Health, 9(2), 1060.

World Health Organization. (2006). The world health report: 2006: Working together for health.

Zachariah, R., Ford, N., Philips, M., Lynch, S., Massaquoi, M., Janssens, V., \& Harries, A. (2009). Task shifting in HIV/AIDS: Opportunities, challenges and proposed actions for sub-saharan africa. Transactions of the Royal Society of Tropical Medicine and Hygiene, 103(6), 549-558. https://doi.org/10.1016/j.trstmh.2008.09.019

\section{Copyrights}

Copyright for this article is retained by the author(s), with first publication rights granted to the journal.

This is an open-access article distributed under the terms and conditions of the Creative Commons Attribution license (http://creativecommons.org/licenses/by/4.0/). 